\title{
Social Responses to Water Management Decisions
}

\author{
Warren E. Walker ${ }^{1,2}$ • Daniel P. Loucks ${ }^{3}$ • Gemma Carr ${ }^{4}$
}

Received: 17 April 2015 / Accepted: 18 June 2015 / Published online: 22 July 2015

(C) Springer International Publishing Switzerland 2015

\begin{abstract}
We suggest that those involved with environmental and water resources planning and management need to consider the social responses as well as the economic and environmental impacts of our decisions. But predicting such responses now, and especially in the future, will not be possible. All we know about the future is that it will differ from the present. This includes the goals or objectives society wishes to achieve. But, in spite of this, decisions have to be made today that shape or influence the future we think we will want. What can policymakers do to better insure that a policy is able to achieve society's objectives over time? One way is to include members of society (or at least their behavior) in the policymaking process. Another way is to make the policy adaptive and include monitoring and learning so that new actions can be taken when conditions change. That is, policies should include provisions for being prepared for changes. In this paper we offer a conceptual model of a coupled social-water system, each component influencing decisions that affect the other over time. We give some examples of just how hard it is to attempt predictions, why, and what can go wrong if those predictions are wrong. And we offer some analytic approaches to policymaking that do not depend on such predictions. These approaches include the use of (1) agent-based models that simulate the behavior of individual or collective entities, (2) stakeholders who represent the social component interacting with computer models of the water systems within a decision support framework or within the framework of a smart game, or (3) dynamic adaptive policies, which rely on monitoring and adapting rather than implementing a fixed policy. All of these approaches can be used to gain insights and understanding of the coupled social and natural components of water resource systems.
\end{abstract}

Daniel P. Loucks

DPL3@cornell.edu

1 Faculty of Technology, Policy and Management, Delft University of Technology, Delft, The Netherlands

2 Faculty of Aerospace Engineering, Delft University of Technology, Delft, The Netherlands

3 School of Civil and Environmental Engineering and Institute of Public Affairs, Cornell University, Ithaca, NY, USA

4 Centre for Water Resource Systems, Vienna University of Technology, Vienna, Austria 
Keywords Water policy · Social responses - Coupled water-social systems · Agent-based models · Smart games $\cdot$ Adaptive policies

\section{Introduction}

Human societies depend on water. Water is needed for food, for energy, for human and ecosystem health, and for the industrial products society produces. Because water has always been critical to the survival and wellbeing of society, over time water has taken on cultural, social, spiritual, and political, as well as economic and public health dimensions. Societies directly and indirectly depend on the quantity, quality, reliability, and affordability of their water supplies. When there is too much or too little water, or when it is too polluted or too expensive, society suffers. These problems seem to be happening more frequently, with more intensity, and for longer durations. Understanding and managing such problems is not easy, in part because the social responses to any decisions intended to solve problems often result in unintended and unexpected other problems. Furthermore, those affected by water management problems often disagree on how best to solve them. It is difficult if not impossible to predict how different stakeholders or parts of society will respond, especially if there is a disagreement on what decisions are best. Nevertheless, to be sustainable, i.e., to have a reasonably long halflife, water management policies must be based on sound science, be affordable, and be compatible with people's values and beliefs (Montanari et al. 2013).

What people want in times of water stress can differ. Finding solutions to reduce this stress requires citizens to become knowledgeable and engage each other in the search for solutions that satisfy public and personal goals and norms. We can simulate the impacts of such solutions on the functioning of water systems over time. With the help of simulation and optimization models, we can identify and evaluate alternative actions society might want to take or decisions its governing institutions might want to make, assuming a future that we can't predict and certainly will contain surprises. What is even more difficult is developing an understanding of the actions that society will take or decisions they will make, given the myriad of social, economic, and environmental impacts stemming from whatever decisions are implemented for some assumed future scenario. Society's decisions are influenced by tradition (e.g., previous decisions), history, and education, and the current cultural, economic, natural, social, and political environment. Society's utility derived from their water systems is not a function of the state of those systems alone. What we ideally want to understand is how society's actions come about, having as input the knowledge of the current status of the water system and other implicit factors that influence the decisionmaking. Why? Because if we can anticipate actions before they take place, we can identify in advance any adverse unintended outcomes that perhaps we can prevent by modifying our decisions, or at least we can be prepared to modify them should undesirable outcomes occur. (This is the idea behind the concept of designing policies to be adaptive (Walker et al. 2001).)

In short, managing water resource systems is often difficult. It is difficult partly because no single academic discipline has all the answers so it requires inter-disciplinary approaches. Its difficulty is compounded by the 'deep uncertainties' in both the future conditions of our water resource systems, and how society will deal with them (Walker et al. 2013). This essay attempts to share some thoughts on the challenges involved when trying to make policy without a complete understanding of, or the ability to predict, coupled water-society system interactions. The relationship between "understanding and prediction" is very important. 
Sometimes understanding is considered the aim of science, and prediction is seen as a practical (however fundamental) problem. But, making water policy for the future has to take place in the face of an inability to make accurate predictions, and only a limited understanding of water-society interactions.

After this introduction, we examine in more detail what is meant by those attempting to couple and better understand the interactions, including the feedbacks that take place over time between water and social systems. What are they and what motivates particular actions? Problems that involve or are based on social values and political considerations are sometimes categorized as 'wicked problems' (Rittel and Webber 1973). Such problems are not easy to formulate or to get agreement on solutions. The actions eventually taken by a society on such problems are often temporary and imperfect, even when they stem from a public debate addressing the shared public concerns. Our objective is to find a way of aiding or facilitating this debate through the use of (non-predictive) models and other analytic tools, not only to understand how society's actions might affect a particular 'water system', but also how the state of that water system might lead to particular societal responses and actions (Wood 2014).

The next section briefly reviews the need for interdisciplinary perspectives when considering coupled water-social systems. This is followed by a brief discussion of approaches to water resources planning and management that include stakeholders (those who are affected by a decision or have the power to influence the decision) in the policy analysis process or that attempt to simulate the behavior of such stakeholders. This can involve stakeholders participating in 'smart games' (Mayer 2009), or the use by stakeholders of interactive graphics-based decision support systems (DSSs) to build and use models of particular water systems. Both of these would attempt to achieve a common 'shared vision' of how the particular water system functions, how stakeholders (the social system) want it to work, and how they might respond to future (uncertain) developments. It could also involve the use of agent-based models (ABMs) to simulate water-society interactions and the interactions of the various actors in society (see Macy and Willer 2002).

To help us think about this we develop a conceptual modeling approach that includes interactions and feedbacks between water and social systems. The conceptualization aids in identifying what is needed to move to the next step - the development of an analytical approach that can help us foresee how society might react to stresses in their water systems, and how decisionmakers can respond to these actions. Next we describe some real-world examples of social-water system interactions. These case studies show that, after societal actions were taken to mitigate stresses in those particular water systems, there were unexpected consequences. These in turn led to reactions by the relevant decisionmaking institutions and, in some cases, to a revaluation of the original mitigation actions taken. The essay ends with some lessons that can be learned, especially by those who tend to ignore what is hard to model (namely, the social and cultural aspects of managing water systems), and some suggestions for future research in social hydrology.

\section{Interdisciplinarity: not a Luxury but a Necessity}

Managing water resource systems is challenging. These systems need to serve people many of whom have different needs and goals, and in an uncertain and changing environment. It is challenging in the sense that no single discipline has all the answers to questions on how best to do this. It is no accident, for example, that the U.S. Army Corps of Engineers and the U.S. Bureau of Reclamation, the two largest water management agencies in the United States, 
employ biologists, ecologists, economists, geologists, historians, lawyers, planners, political scientists, and sociologists among other disciplines, as well as what its name suggests, engineers and hydrologists. For example, the collection of disciplines involved in understanding the fate and transport of pollutants in a watershed could include hydrology, meteorology, geology, geomorphology, soil science, biological science, and plant sciences. Each of these disciplines provides increased understanding of how watersheds function. In the search for reducing or controlling such pollutants, one benefits from additional knowledge in the disciplines of anthropology, biological, chemical and environmental engineering, economics, law, sociology, political science, and planning. Research spanning these and other applicable academic disciplines is helpful for developing our understanding of integrated water resources systems (Jeffrey 2003). Interdisciplinarity is therefore a consequence of the kind of complex and challenging problems that water science researchers and managers are engaged in (Klein 1990). Such interdisciplinarity also offers new opportunities for identifying novel science questions that exist across and among multiple disciplines (Blöschl et al. 2012).

One of these questions requiring a multidisciplinary response is being addressed by those working on socio-hydrology; i.e., investigating how social-water systems co-evolve, and the dynamics of these systems (Sivapalan et al. 2012). The field of socio-hydrology brings together engineers, sociologists, economists, and natural scientists to unravel the complexity of coupled water-social systems. Yet knowledge of such systems is not limited to researchers. Everyone who lives and works with water understands at least part of that water system. This knowledge can be added to that of scientists through approaches designed to capture this stakeholder knowledge (Kreuger et al. 2014).

\section{Including Stakeholders}

In the early 1980s, it became possible to develop and use interactive graphics based computeruser interfaces. These interfaces link the social or human component to physically-based models of various systems, including water resource systems. Such interfaces give stakeholders the capability of not only participating in the building of system models (often interactively) and thus being aware of their assumptions and limitations, but also the capability of exploring alternative designs and operating policies affecting the performance of the system. While the water system component is coded, the social system component is the stakeholders involved in or observing the building, modifying, and running the interactive computer program, entering its input data, and observing, and reacting to, the results. Computer algorithms make analyses possible, and the actual involvement of stakeholders make synthesis - the creation of new ideas and options - possible.

Interactive decision support systems (DSSs) are now in wide use. Shared Vision Planning (SVP) and Computer-Aided Dispute Resolution, which combine traditional water resources planning, structured stakeholder participation, and collaborative computer modeling, have become prominent activities of numerous public agencies and consulting firms. For example, the Shared Vision Planning program at the Institute for Water Resources (IWR) of the U.S. Army Corps of Engineers emphasizes public involvement in water resources management and the use of collectively developed computer models along with Corps planning principles (Cardwell et al. 2008). Their SVP exercises aim to improve the economic, environmental, and social outcomes of water management decisions. Involving stakeholders throughout the SVP process can facilitate a common understanding of a natural resource system and help 
stakeholders reach a management consensus that satisfies multiple interests. Shared Vision Planning allows IWR personnel to work directly with stakeholders to find acceptable solutions to issues surrounding the management of water resources. They have applied this approach in numerous case studies across the U.S. with varying degrees of success (see www.sharedvisionplanning.us).

Indeed, many of the water resource systems software programs available and in use today from public and private organizations (e.g., DHI, Deltares, Universidad Politécnica de Valencia, USEPA, CADSWES, Colorado State University, University of California at Davis) are interactive, data driven, decision support, or shared vision planning systems. Collaborative modeling with stakeholders brings together a wide collection of interest groups so that knowledge and views on the socio-hydrological system are made explicit and brought into the scientific arena (Voinov and Bousquet 2010). Other forms of collaborative groups, such as mixed stakeholder working groups or expert panels, also bring together distributed knowledge and create a new, more complete, understanding of issues (Lane 2014).

Modeling with stakeholders provides an approach for making knowledge explicit, integrating information from a wide variety of sources and interest groups, and identifying strategies that are appropriate and acceptable for the people living and working in a watershed under the current conditions. Yet this approach is not able to anticipate how societal decision-making might respond to future changes in water systems. What is needed is an approach that is able to identify decisions to be made in the short term, the impact these decisions will have on the socio-hydrological system, and future decisions that should be made in response to these new conditions. Three promising approaches with these characteristics are discussed briefly in the following paragraphs (with references to more detailed information). The approaches are (1) Agent-Based Models, (2) Smart Games, and (3) Dynamic Adaptive Policy Pathways.

\subsection{Agent-Based Models}

An agent-based model (ABM) is a type of computational model that simulates the actions and interactions of 'autonomous agents' (either individuals, or collective entities such as organizations or groups) in order to assess their effects on the system as a whole. The goal of an $\mathrm{ABM}$ is to search for explanatory insight into the collective behavior of agents obeying simple rules. A key notion is that simple behavioral rules generate complex (emergent) behavior. As shown by real-world examples later in this paper, societal responses to policy decisions are rarely taken into account by policymakers, but they can determine the success or failure of the policy. Although human group processes are highly complex, non-linear, path dependent, and self-organizing, the ABM approach attempts to understand these dynamics by modeling them as emergent properties of interaction among adaptive agents who influence one another in response to the influences they receive (e.g., from the decisions policymakers make).

ABMs have been used in many fields, and for many purposes. For example, Bouarfa et al. (2013) used it to help improve air transport safety by providing insights into the complex socio-technical air transport system, which involves interactions among human operators, technical systems, and procedures. But, our interest is in the interaction of natural systems with social systems. For example, Monticino et al. (2007) used ABM to examine forest ecosystems and the encroachment of residential, commercial and industrial development. They modeled the complex interactions between land-use change decisions and ecosystems, and how the consequences of these decisions may then influence human values and subsequent decisions. They defined four classes of stakeholders: Landowner agents, developer 
agents, homeowner agents, and government agents. Several types of agents were defined within each agent class. Each agent type was characterized by a value structure that influenced the actions selected by that agent. This type of ABM falls within a category of modeling that is sometimes known as 'computational sociology' (Macy and Willer 2002).

\subsection{Smart Games}

Another way of obtaining insights into how human behavior might affect policy decisions is to include real humans in a gaming environment (instead of representing them inside of a computer simulation model). Mayer (2009) reviews the development of gaming for purposes such as public policy analysis and planning. He concludes that the success of gaming for policymaking derives largely from its unique power to capture and integrate both the technicalphysical and the social-political complexities of policy problems.

Smart games developed out of the man-machine 'war games' that were played during the Cold War at defense-related think tanks like the RAND Corporation. In the 1970s, RAND analysts broadened their scope considerably, applying them to areas such as urban planning. But, their use was somewhat limited by the slowness of the computers and poor humancomputer interfaces. By the 1990s, global environmental change and its impact on, for example, forests, river basins, and flooding became major issues of concern and debate in the science-policy interface. What seemed to be required was a constructive negotiation and learning process among scientists, and between scientists and stakeholders that was evidence and science based. In the Netherlands, Jac Geurts (1993) proposed gaming style 'policy exercises' as a form of environmental war gaming, combining computer intelligence with human and social intelligence. But, it was not until computer games as entertainment became extremely popular that the 'serious game' notion of using the technology and concepts derived from computer games for non-entertainment purposes such as policymaking in the fields of health care, education, water management, etc. caught on (Michael and Chen 2006).

The use of smart games (as opposed to the use of more sophisticated analytic methods such as optimization models or simulations) is based on the fact that it is now clear that policymaking is not a rational top-down process in which governments are able to implement optimal solutions to well-defined problems. Instead, policies are increasingly being seen to be made via policy networks with loosely connected and interdependent actors that interact in the policy process (Scharpf 1997). Many of the actors are powerful and deliberately attempt to influence the outcome of the political process to their own advantage. As Mayer (2009) put it: "To some extent, real-world policy making resembles a strategic (messy) game, like a boxing contest lasting several rounds (albeit with changing players and ambiguous rules)." By using real people, instead of computer models, smart games are able to incorporate the unpredictable, strategic, and frequently irrational behavior exhibited by real people and organizations. According to Mayer (2009), "gaming is probably the only method in the policy analysis toolbox where real people - as actors or stakeholders - can be an intrinsic part of a computer model. Not as digital agents, but as real players with stakes, tacit knowledge, emotions, intuitions, and so on."

\subsection{Dynamic Adaptive Policy Pathways}

Both ABM and Smart Games use models to develop a static plan. Such plans may perform well under expected conditions, but they may be ineffective under changing or surprising 
conditions. Moreover, as the future unfolds policymakers can learn and respond to new situations by adapting the plans to improve their performance. Also, societal perspectives and preferences may change over time, including stakeholders' interests and their evaluation of plans. An approach to policymaking that takes into account social responses but is not based on developing a fixed, static policy, falls into the category called "dynamic adaptive policies" - first outlined by Walker, et al. (2001). Their guiding principle is that policies should be adaptive and robust across a range of plausible futures, including changes in society and societal reactions to policies. Since the seminal paper in 2001, various areas of application for adaptive policies have been explored, including flood risk management in the Netherlands in light of climate change (Rahman et al. 2008) and policies with respect to long-term problems in the fields of road, rail, and air transport (Marchau et al. 2010).

The Dynamic Adaptive Policy Pathways (DAPP) approach extends the original concept to explicitly consider the timing of actions. The approach asks the question "under what conditions will a given plan fail"? These are conditions (also called "adaptation tipping points" (Kwadijk et al. 2010) or 'sell-by-dates') under which the magnitude of external change is such that the current plan can no longer meet its objectives and new actions are needed to achieve the objectives. When this occurs in time (and even if it occurs) is unknown - it is dependent on what happens in the world external to the system. As a result, a pathway emerges. DAPP is described by Haasnoot, et al. (2013). The process is illustrated in Fig. 1.

DAPP begins with the identification of objectives, constraints, and uncertainties that are relevant for decisionmaking. The uncertainties are then used to generate an ensemble of plausible futures. These futures are compared with the objectives to see if problems arise or if opportunities occur. This determines if and when policy actions are needed. The performance of each of the actions and pathways is assessed in light of the defined objectives to determine its adaptation tipping point. Once a set of actions seems adequate, potential pathways (a sequence of actions) can be constructed, and subsequently one or more preferred pathways can be selected as input for a dynamic robust plan. The aim of this plan is to stay on

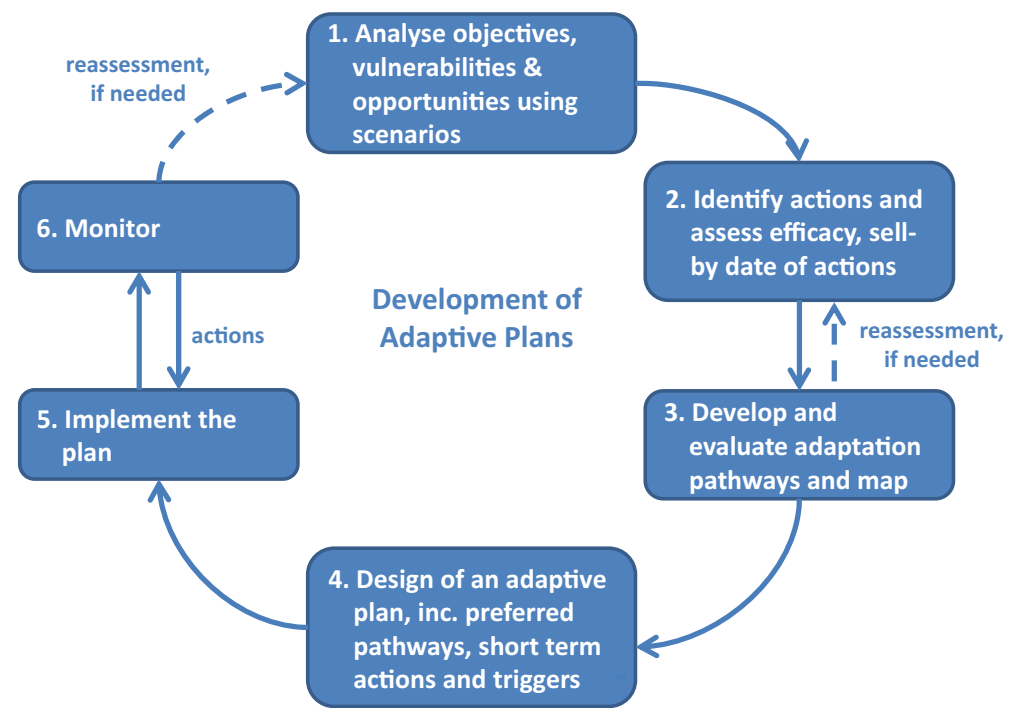

Fig. 1 The dynamic adaptive policy pathways approach (based on Haasnoot et al. 2013) 
the preferred pathway as long as possible. For this purpose, contingency actions are specified and a trigger for each contingency action is specified and monitored (Kwakkel et al. 2010).

In designing the DAPP, the primary question asked by the analysts (at the time of making the policy) is 'how can this policy fail?' - i.e., what are its vulnerabilities; what could happen (surprises, 'Black Swans') that would make the policy fail to meet its stated objectives. Based on the answer to this question, changes to the policy are specified, to be triggered when the monitoring indicates the basic policy might be failing to meet the then-current objectives (i.e., it is at a tipping point). So, the hope is that we will be prepared in advance for whatever situation presents itself. The approach aims at building flexibility into the overall adaptation strategy (rather than into the individual actions) by sequencing the implementation of actions over time in such a way that the system is adapted over time to changing climate, social, economic conditions, etc., and options are left open to deal with a range of plausible future conditions.

\section{Coupled Water-Social Systems}

Let Fig. 2 represent a water system. This figure depicts a rather complex multi-purpose multicomponent system. Even the management of land and water in a small watershed may present a challenge to those who live there, and derive their water from it. However, the major complexity may be in the unseen social system associated with this, and any, water resource system.

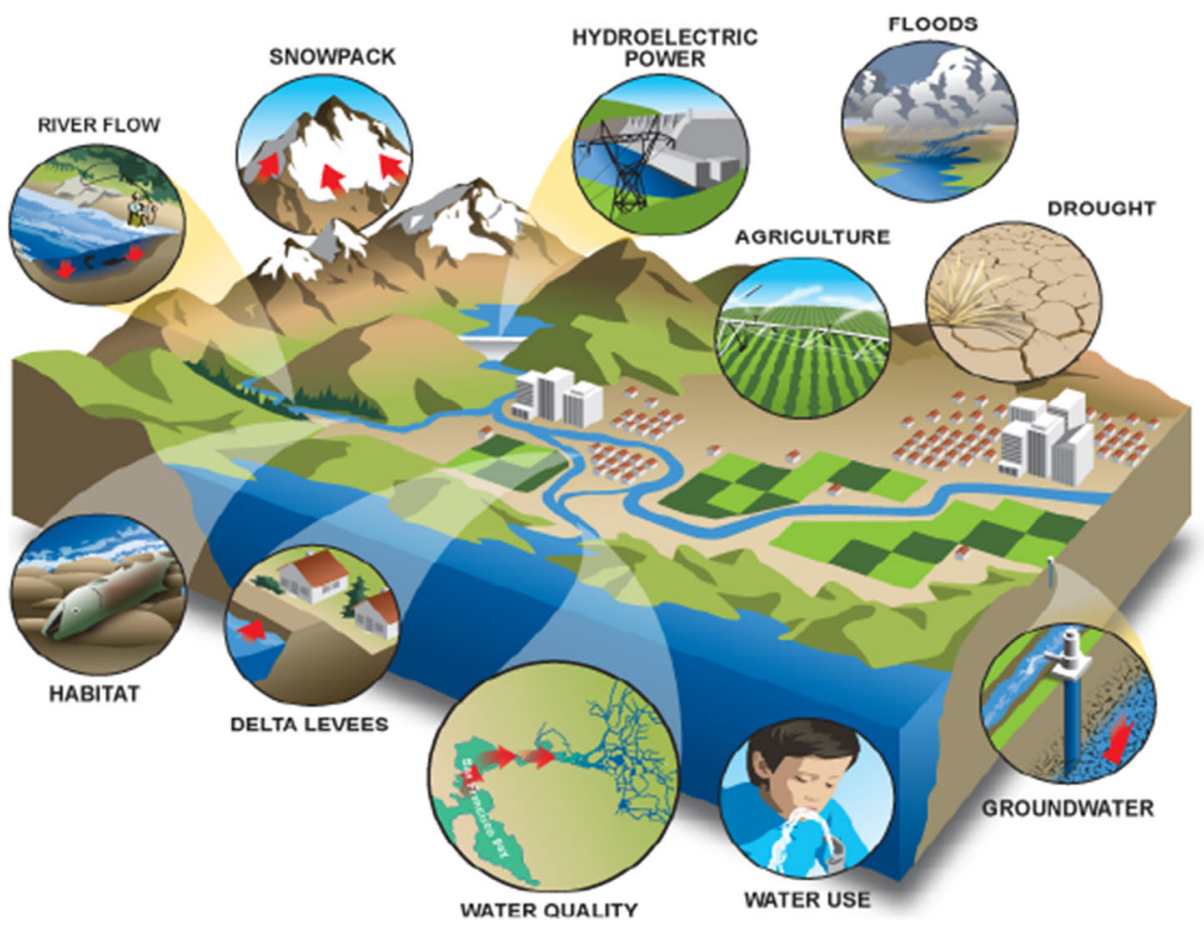

Fig. 2 A multi-purpose multi-component water system. http://www.water.ca.gov/climatechange/factsheet.cfm 
Let Fig. 3 represent a social system oriented toward managing all or a portion of that water system.

Actions taken by social institutions to change the state or performance of a water system are presumably intended to get beneficial results. Any less than desired state or performance of the water system motivates change. Many of the changes to developed water resource systems that occur over time are the result less of natural processes but more of actions taken by people, i.e., the social system.

Figure 4 illustrates such a coupled water-social system. What we would like to understand is how particular actions come about, having as input the current knowledge of the status of the water system and other implicit factors that influence the decisionmaking. Sometimes such social actions involving water systems result in unintended and undesired consequences. This could be due to ignorance regarding how a particular water system functions, so as one learns more one can adapt more (as planned for using adaptive policies), due to changes in what people (stakeholders) want over time, or due to changes in the world that produce changes in the water system and what we want from it.

Any event anywhere in the world can suddenly or slowly change what a society values and desires or considers important. Examples of a sudden event are the tsunami of March 11, 2011 damaging the Fukushima Daiichi nuclear power plant in Japan, and the 9/11/2001 terrorist attacks in New York City and Washington, D.C. An example of a slowly changing event is the environmental movement resulting in part from the publishing of books such as Rachel Carlson's Silent Spring, beginning in the early 1970s and still occurring today under the banner of sustainability and security. It is, therefore, important to understand that the watersocial system dynamics are not only triggered by what is (endogenously) happening in the system, but also, and in some cases in a dominant way, by external (exogenous) factors. What is to be considered endogenous or exogenous is determined by the definition of the boundaries of the system, i.e., what engineers call 'control volume'. Nevertheless, it is clear that, in practice, there will always be important exogenous factors that are outside the boundaries of the water-social system under study, but will affect the functioning of, and decisionmaking

Fig. 3 A social system involving multiple stakeholders who care and are impacted by how well their water system functions. (Loucks and van Beek, Water Resources Systems, UNESCO, 2005)

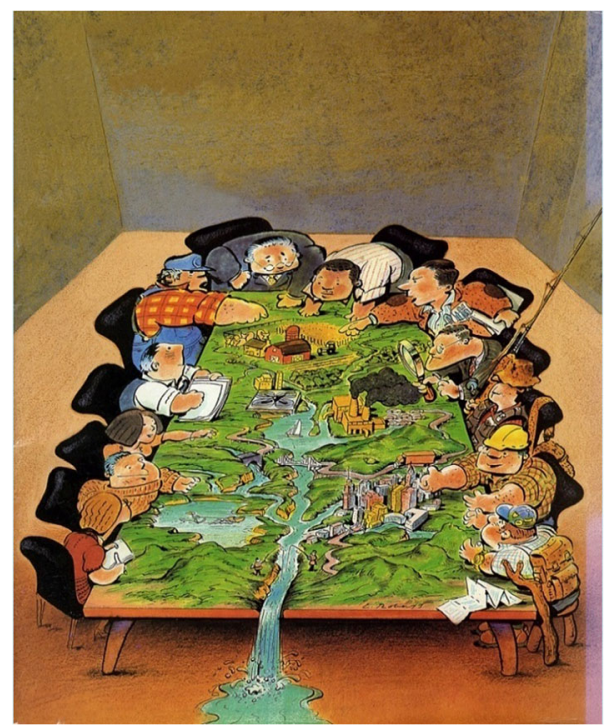




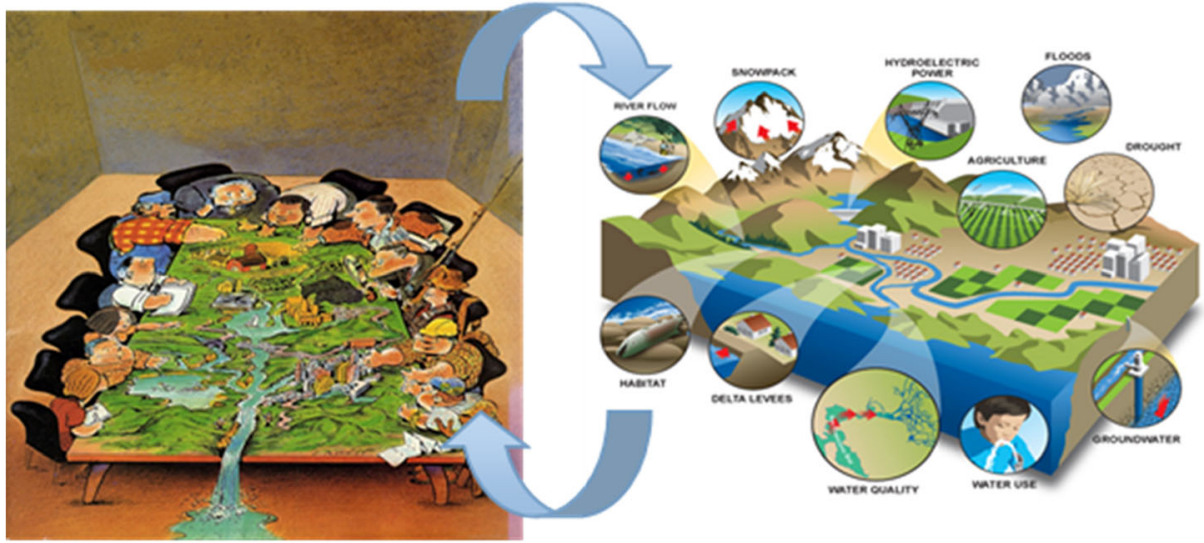

Fig. 4 A coupled water-social system. The state or performance of the water system motivates actions by society, and those actions (represented by the upper arrow) in turn alter the state of the water system as perceived (represented by the lower arrow) by the social system

about, the system. Taleb (2007) calls these events 'Black Swans'. He defines a Black Swan event as one that lies outside the realm of regular expectations (i.e., "nothing in the past can convincingly point to its possibility"), carries an extreme impact, and is explainable only after the fact (i.e., through retrospective, not prospective, predictability).

As illustrated in Fig. 5, after management actions have been made by applicable institutions created by society, some groups in society may be dissatisfied with the performance of the water system. This can lead to public demands for further actions by the social system to alter the design, management, or operation of the water system so as to better meet their goals or expectations. This is a dynamic process. Yet, planning for water systems is generally based on finding an 'optimal' policy based on a predicted future. It is unlikely that it will ever be possible to predict the actions that society might take with respect to mitigating any stresses in their water system or in attempting to improve its performance. So, this paper suggests that plans should be adaptive - devised not to be optimal for a best estimate future, but robust across a range of plausible futures. Such policies will indicate near term actions that combine those that are time urgent, those that make important commitments to shape the future, and those that preserve needed flexibility for the future. In doing so, the plans account for deep uncertainties in social behavior and exogenous events by incorporating flexibility and learning mechanisms that enable adaptation throughout implementation.

\section{Modeling Water-Society Interactions}

There are a number of papers presenting models of interactions between natural and social processes. For example, Di Baldassarre et al. (2013) and Viglione et al. (2014) developed and used a simulation model to examine the dynamics of a human-flood system. The model was able to reproduce reciprocal effects between floods and people as well as the emergence of typical floodplain development patterns. Monticino et al. (2007) used a multi-agent based approach (related to agent-based modeling) to study the complex interactions between development decisions and ecosystem responses, and how the environmental consequences of these decisions influence human values and subsequent decisions. In this section we limit 


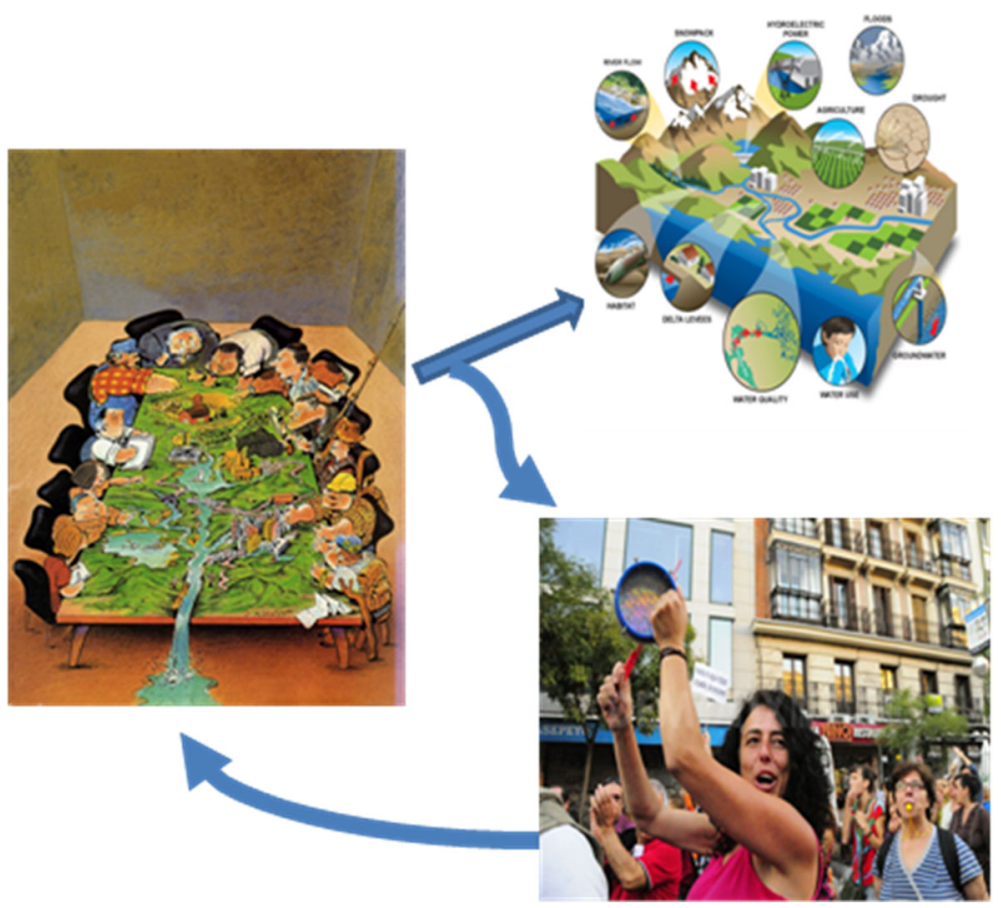

Fig. 5 Actions taken by society (on the left) can have intended and unintended consequences. Unintended consequences of social actions could result in public pressure (lower right) to take further actions

ourselves to conceptual modeling in an effort to identify what we need to know in order to model the coupled interactions between physical (e.g., hydrologic) and social systems.

Consider a water resource system (Fig. 6) containing a potential reservoir site upstream from a single demand site along a river as illustrated in Fig. 5.

Using historical flow data a storage-water yield function can be constructed for the reservoir site. This function, $Y(K)$, identifies the historical maximum reliable water release flow, $y$, that can be obtained from the reservoir having an active storage volume capacity of $K$. The larger the storage volume capacity $K$, the greater will be the value of the yield, $y$, up to a point. The annual utility or benefit, however measured, $U_{\mathrm{Y}}(y)$, obtained at the downstream demand site depends on the amount of that reliable yield, $y$, allocated to it. Water released in excess of the allocated yield continues downstream.

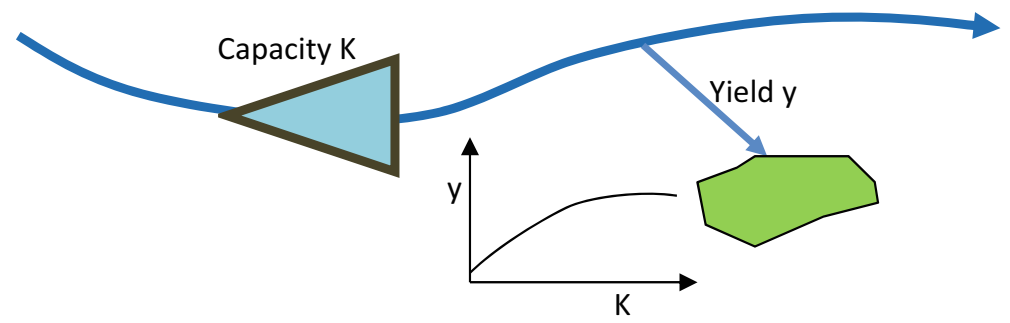

Fig. 6 A water system consisting of a potential reservoir having a storage capacity $\mathrm{K}$ and a dependable release, or yield, of $\mathrm{y}$ that is a function of $\mathrm{K}$, that is allocated to a single water user downstream 
While the utility derived from any yield may increase with increases in the yield, a greater yield requires a larger reservoir capacity $K$, and this costs money. Of interest, at least for economists, would be the values of $y$ and $K$ that maximize the net utility derived from the water system. Assuming the marginal utility of the water yield is always non-negative, and the marginal disutility $U_{\mathrm{K}}(K)$ (because of its cost) of the reservoir storage volume capacity $K$ is always negative, the optimal values of $y$ and $K$ result from finding the maximum of $U_{\mathrm{Y}}(y)-U_{\mathrm{K}}(K)$, where $y$ is defined as a function, $Y(K)$, of $K$. Thus, we wish to

$$
\operatorname{Maximize} U_{\mathrm{Y}}(y)--U_{\mathrm{K}}(K)
$$

Subject to:

$$
y=Y(K)
$$

How utility is defined is likely to differ among different stakeholders. In addition it is likely to change with time. Even if decisionmakers accept a common measure of utility, and even if they have asked for the information provided by this model, they may not accept this model's solution. Whatever it is they have told the modelers to do, by the time it is done decisionmakers may ignore their results and decide to invest their money in other ways that give them more in return.

Assume they now want to build the reservoir also for flood control purposes. If model builders knew in advance that flood control might be of interest, they could easily have included that possibility in their analysis. For example, assuming the variable $K_{\mathrm{f}}$ is that portion of the total active storage capacity, $K$, used for flood control, and $U_{\mathrm{F}}\left(K_{\mathrm{f}}\right)$ is a measure of the annual utility derived from flood control storage, the revised model might look like.

$$
\operatorname{Max} U_{\mathrm{Y}}(y)+U_{\mathrm{F}}\left(K_{\mathrm{f}}\right)-U_{\mathrm{K}}(K)
$$

where

$$
y=Y\left(K-K_{\mathrm{f}}\right)
$$

Can modelers better serve decisionmakers by building into their models the capability of generating new ideas, new options that were not being considered or even thought of originally but that might be preferred by decisionmakers? How could one do this? How could the model defined by Eqs. (1) and (2) without the variable $K_{\mathrm{f}}$, be altered so that its solution would include the idea that maybe flood control storage, $K_{\mathrm{f}}$, might also be considered? If it did, then the model defined by Eqs. (3) and (4) could be used to determine the amount of flood control storage that is considered best given the assumed utility functions. In addition, how could these equations be expanded to consider society actions and unpredictable external changes (Black Swans)?

In place of models such as defined above, consider a society action or decision function, $D(\boldsymbol{X}(\mathrm{t}), \odot(\mathrm{t}))$, whose arguments are all the information pertaining to the state of the water resource system in the current time period $\mathrm{t}$, denoted as the vector $\boldsymbol{X}(\mathrm{t})$, and other economic, environmental, social and political considerations, $\odot(t)$. The vector $\boldsymbol{X}(\mathrm{t})$ represents knowledge that is known, observable, and explicitly stated at time t (e.g., precipitation, flow, and water quality data, infrastructure capacities and operating policies, land uses, groundwater, lake and reservoir water storage volumes, etc.). The vector, (-) (t), represents everything else that influences the decisions $\boldsymbol{Z}(\mathrm{t})$ made by those who make decisions affecting $\boldsymbol{X}(\mathrm{t})$. This vector includes knowledge that is hidden, or non-explicit, perhaps because it might be contentious, 
such as wastewater reuse (see for example, Carr and Potter 2013) or flood management options that allocate flood risks to different land owners differently, or exogenous to the system under study, such as environmental sensitivity and equity among stakeholder costs and benefits.

Conceptually, what we would like to be able to study and solve is a coupled water - social system; letting the vector $\boldsymbol{X}(\mathrm{t})$ represent the current decision variable values related to the water system, and the vector $\boldsymbol{Z}(\mathrm{t})$ represent the actions the social system takes in period $\mathrm{t}$ in response to $\boldsymbol{X}(\mathrm{t})$, and $N U_{t}(\boldsymbol{X}(\mathrm{t}))$ a net utility criterion that decisionmakers want to maximize in each time period t. Then the goal would be to:

$$
\operatorname{Maximize} \sum_{t} N U_{\mathrm{t}}(X(\mathrm{t}+1)) \alpha_{\mathrm{t}}
$$

subject to, for each period t:

$$
\boldsymbol{Z}(\mathrm{t})=D(\boldsymbol{X}(\mathrm{t}), \Theta(\mathrm{t}))(\text { the social system component of the model) }
$$

$$
\boldsymbol{X}(\mathrm{t}) \text { feasible (the water system component of the model) }
$$

$\boldsymbol{X}(\mathrm{t}+1)=T(\boldsymbol{Z}(\mathrm{t}), \boldsymbol{X}(\mathrm{t}), \varepsilon, \mathrm{t})$ (transition function modifying the water model and values of its variables)

where $\alpha_{\mathrm{t}}$ is a discount factor, $\varepsilon$ is the unknown, unpredictable, and unimagined surprise component. The set of unknown objective functions $N U_{\mathrm{t}}\left(^{*}\right)$ can change over time, hence the time index subscript $t$.

This coupled interaction between these changing and partly uncertain water and social systems is more realistically characterized by an adaptive decisionmaking process. Decisions are made in response to the current state of the system, $\boldsymbol{X}(\mathrm{t})$. The impacts of such decisions are observed in time, and result in new conditions, $\boldsymbol{X}(\mathrm{t}+1)$. Given the current state of the water system, $\boldsymbol{X}(\mathrm{t})$, and the considerations contained in the 'everything else' vector $\odot(\mathrm{t})$, the social system makes a decision, $\boldsymbol{Z}(\mathrm{t})$, that is based on what they think will happen, i.e., the expected value of $\boldsymbol{X}(\mathrm{t}+1)$, denoted as $\mathrm{E}[X(\mathrm{t}+1)]$.

Maximize $N U_{\mathrm{t}}(\mathrm{E}[X(\mathrm{t}+1)])$

$$
\boldsymbol{Z}(\mathrm{t})=D(\boldsymbol{X}(\mathrm{t}),(\mathrm{)}(\mathrm{t}))(\text { the social system component of the model) }
$$

$$
\boldsymbol{X}(\mathrm{t}) \text { feasible (the water system component of the model) }
$$

$\mathrm{E}[\boldsymbol{X}(\mathrm{t}+1)]=T(\boldsymbol{Z}(\mathrm{t}), \boldsymbol{X}(\mathrm{t}), \mathrm{t})$ (transition function modifying the water model and values of its variables)

But the actual next state of the water system may contain some surprises, or unintentional impacts.

$\boldsymbol{X}(\mathrm{t}+1)=T(\boldsymbol{Z}(\mathrm{t}), \boldsymbol{X}(\mathrm{t}), \varepsilon, \mathrm{t}) \quad($ transition function modifying the water model and values of its variables)

The above is more or less the Dynamic Adaptive Policy Pathways (DAPP) process described above. 


\section{Examples of social-water system interactions}

Each of the examples cited below involve decisions and stakeholder reactions or feedbacks that result in new decisions. Most of these new decisions were not envisioned when the first set of decisions were made. Referring to the coupled water-society models above, the inputs represented by $\odot$ and $N U$ changed. This in turn changed the decisions $\boldsymbol{Z}$ in an effort to improve, we assume, the performance of the water system. These examples suggest that there often is no one obvious best solution to problems involving water, if for no other reason than unpredictable changes in what people want, i.e., $N U$, and their components, $\odot$, over time. Droughts, floods, or polluted water can trigger individual and community concerns, but the path taken to address such concerns, successfully or otherwise, is often unpredictable. In other words, the functions $N U$ and $D$, and thus the output $Z$, will likely differ over time for each society and among different societies or communities.

\subsection{The Hudson River, New York}

In the 1960s, before the so called environmental movement, many rivers in the U.S. were polluted. The oil and chemical pollution of one such river, the Hudson, Fig. 7, exceeded 170 times the safe limits $(\boldsymbol{X})$. Decisions $(\boldsymbol{Z})$ made at that time were to allow pollutant discharges to continue, perhaps in the interest of encouraging economic development in spite of environment and health risks. But some in society had a different vision. One was the folksinger and activist Pete Seeger. He, with the support of his guitar and other artists and activists, raised the money needed to build a 32-m-long sailing ship, similar in design to those used in river during the eighteenth and nineteenth centuries to carry goods and passengers. The ship named Clearwater was launched in 1969 to help promote the mission of cleaning up the river. Due in part to his leadership in creating a broad base of support (-) ) for improving the environment, including the quality of water in the Hudson, decisions $(\boldsymbol{Z})$ were made to dredge and restore the river almost to its original condition. Today the Clearwater still sails on the Hudson, on cleaner if not clear water, serving as a floating classroom, teaching schoolchildren about the river and the need for its care.
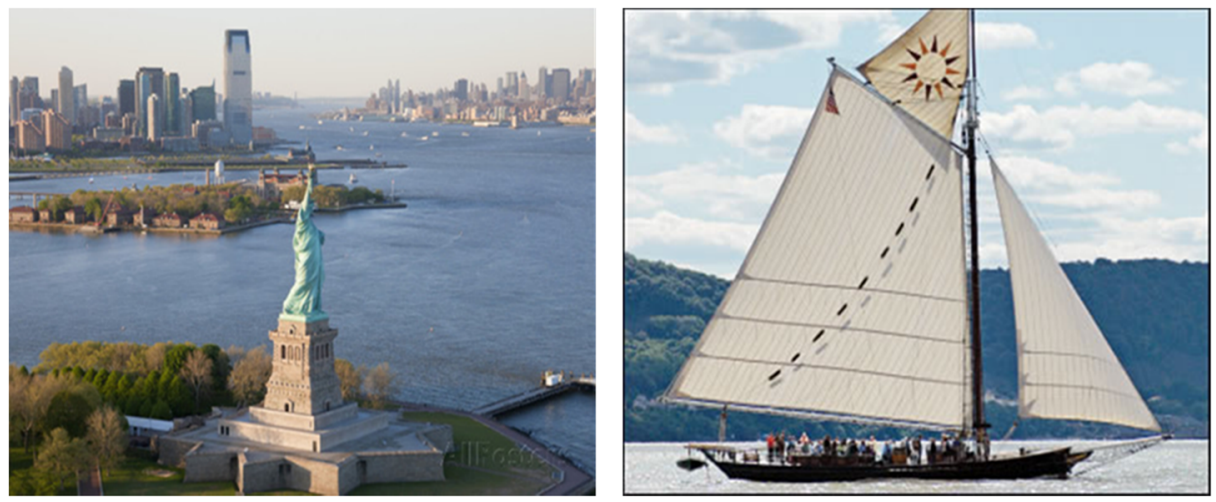

Fig. 7 Hudson River in New York, USA, and the Clearwater ship built in the 1960s to generate support for a cleaner river. (http://www.allposters.com/-sp/Statue-of-Liberty) (http://en.wikipedia.org/wiki/Hudson_River Sloop_Clearwater) 


\subsection{The Murray-Darling River Basin}

Unlike the Hudson, the Murray-Darling, the largest river system in Australia, flows through arid country, is vulnerable to drought, and has been the subject of conflicting demands for its diminishing flow. The question of governance of the Murray-Darling Basin (MDB), and how to allocate its water, Fig. 8 , has been debated by state and federal governments, farmers, and environmental activists for decades. A combination of a decade-long drought and overuse of the water, mainly for irrigation, has caused the river to dry up in many places. In 2010, the Murray-Darling Basin Authority (MDBA), which had been established to try to restore the environmental and economic health of the basin $(\boldsymbol{X}(\mathrm{t}))$, produced a plan $(\boldsymbol{Z}(\mathrm{t}))$. The plan was designed to limit the quantity of water that could be taken from the basin for irrigation purposes, and set standards for water quality and salinity. There was also a scheme for water trading across the basin. An overall goal was to minimize the adverse social and economic impacts while achieving the plan's environmental improvement goals.

When the basin plan was made public it sparked intense reaction $(\odot(t))$, especially from farmers and wine growers in the region, but also in the parliament. Environmentalists referred to the river system as a living creature whose very existence was at risk. They argued for increased environmental flow allocations, whereas many farmers threatened legal action should the authority proceed with its plan to restrict withdrawals so as to protect the environmental assets and ecosystems. These political pressures resulted in a revised plan $(\boldsymbol{Z}(\mathrm{t}+1))$.

Once again public pressure from stakeholders having different goals and opinions on how the river should be managed ( () (t)) was felt by society's established institution, MDBA, and resulted in new programs and additional funding, $\boldsymbol{Z}(\mathrm{t}+1)$ that included more options than those being considered in the original basin plan, $\boldsymbol{Z}(\mathrm{t})$. Time will tell if these revised decisions will be sustainable.

\subsection{The Everglades in Florida, USA}

The Everglades Fig. 9, is a very large flat watershed that covers much of southern Florida. During the wet season, water flows in a very wide and shallow river, approximately 100 miles

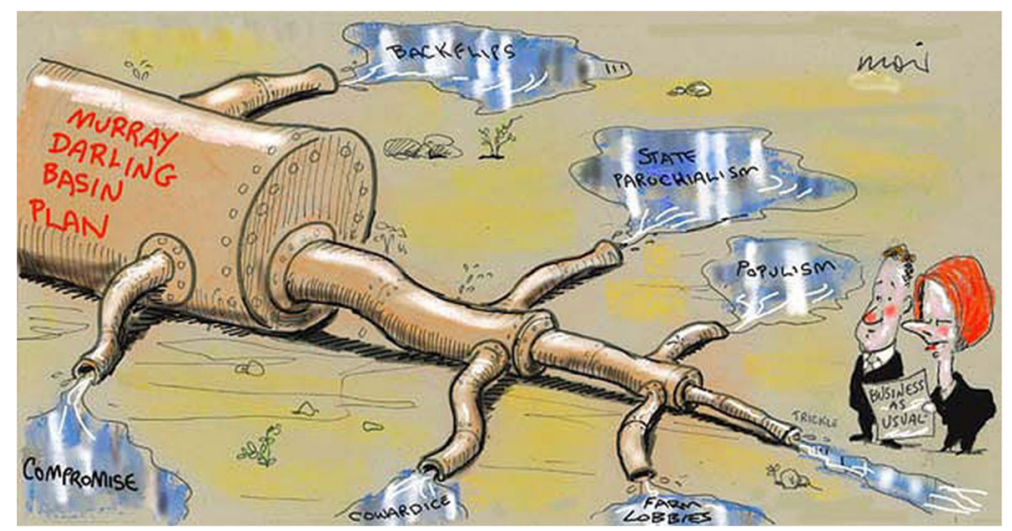

Fig. 8 An over allocated Murray-Darling River in Eastern Australia. http://www.sauer-thompson.com/archives/ opinion/environmentecology 


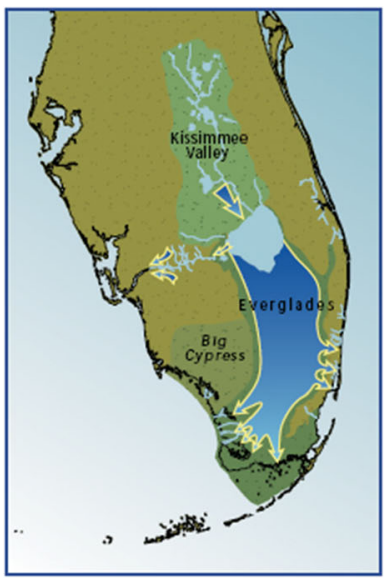

Pre-Drainage Flow

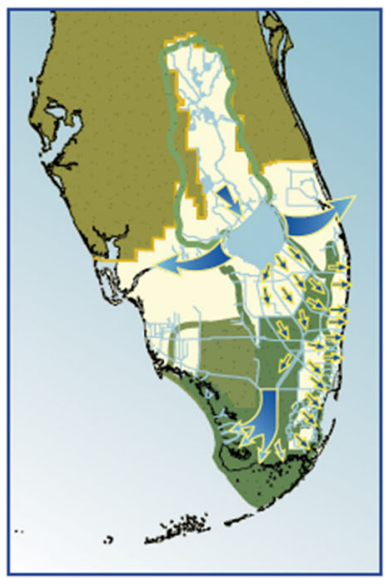

Current Flow

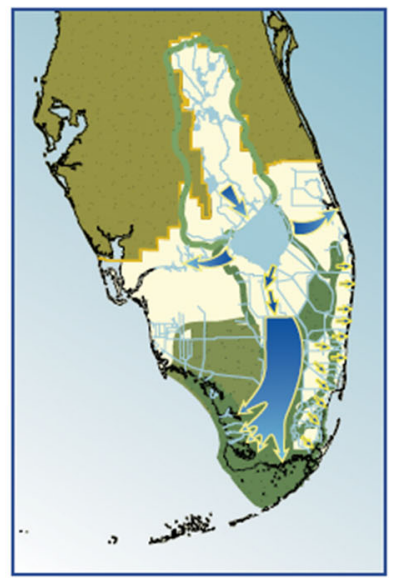

Restored Flow

Fig. 9 Altering the way water is managed as a means of restoring the vitality of the ecosystem in the Florida Everglades, as detailed in the Comprehensive Everglades Restoration Plan. (Source: USACE, Jacksonville District; South Florida Water Management District)

$(160 \mathrm{~km})$ long and 60 miles $(97 \mathrm{~km})$ wide. The land gradually slopes toward Florida Bay, the historical destination of most of the water leaving the Everglades. Before drainage attempts, the Everglades comprised 4,000 mile $^{2}\left(10,000 \mathrm{~km}^{2}\right)$, taking up a third of the Florida peninsula. Its ecosystem is unique. Political pressure $\left(\odot(\mathbf{t})\right.$ and $\left.N U_{t}\right)$ to drain $(\boldsymbol{Z}(\mathrm{t}))$ much of the region for agriculture and urban development led to the construction of 1,400 miles $(2,300 \mathrm{~km})$ of canals and levees, and hundreds of pumping stations and other water control devices. As a consequence the water no longer flows where it used to, and the ecosystem is degraded. The unintended consequences, a degraded ecosystem $\boldsymbol{X}(\mathrm{t}+1)$, were of little concern, until the environmental awakening (an altered $-(\mathbf{t})$ and $N U_{t}$ ) beginning in the 1970s. In the 1980s, decisions $(\boldsymbol{Z}(\mathrm{t}+1))$ were taken to restore the Everglades ecosystem, or what was left of it. Currently, the restoration of the Everglades is an ongoing effort to remedy damage inflicted on the environment of southern Florida during the 20th century. This expensive and comprehensive environmental repair attempt is an example of how objectives or goals of people can change over time, leading to decisions to undo previous decisions, made in this case when the condition of the natural environment was not of concern. Would the DAPP approach have reduced the time, and thus cost, of making this policy change? Monitoring and periodic reassessments might have triggered a policy change when, as in this case, objectives began to change.

\subsection{Privatization of Public Water Systems (Fig. 10)}

Entrusting a profit-driven company with an indispensable public service has always been a controversial concept, primarily because of the possible contradiction between short-term profit maximization and long-term needs to protect infrastructure and essential natural resources. The profit motive may provide private water companies with incentives to avoid measures aimed at conservation and demand reduction, since incomes depend upon volumes of water sold. The international development banks have been promoting privatization, which inevitably involves rate increases. As expected, there has been public opposition to not only 


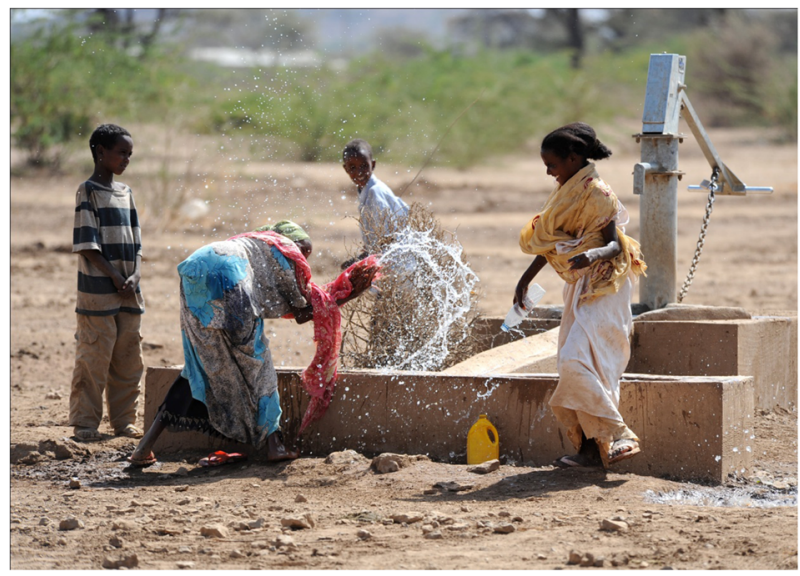

Fig. 10 Question: Will cleaner, cheaper, more reliable and accessible water be provided by public or private organizations? (http://en.wikipedia.org/wiki/Water_supply_and_sanitation_in_Ethiopia)

the rate hikes, but also to the idea of selling of a public good for private profit. What has been unexpected is the severity of this opposition.

n Cochabamba, Bolivia, Bechtel (a large engineering company) promised to extend water access to many previously unserved communities. The company took over the repair and maintenance of local wells, water pumps, and the public system infrastructure that was already in place, and added to the existing infrastructure to reach new communities, $\boldsymbol{Z}(\mathrm{t})$ given $\boldsymbol{X}(\mathrm{t})$. The costs for these improvements and additions were passed on to customers, sometimes doubling the cost many people had previously been paying when water systems were operated by the government. Many were unable to pay the higher rates, and even though water was now more available to them, they couldn't access it because they couldn't afford to.

In 2000, riots broke out in Cochabamba as people became increasingly upset that a private, foreign-owned conglomerate was raising water prices $(\odot(t))$. The violence resulted in Bechtel being forced out $(\boldsymbol{Z}(\mathrm{t}+1))$, causing interruptions in water delivery services in the area, and reduced foreign investment in the country.

Although responsibility for managing water in Cochabamba returned to the public utility, water privatization initiatives were implemented in other regions of the country. Like their fellow countrymen in Cochabamba, residents of those regions took to the streets to protest against high water rates, forcing the government to cancel private water delivery contracts. The result: tens of thousands of households were left with no water $(\boldsymbol{X}(\mathrm{t}+1))$ while the local government attempted to resume water delivery.

The Bolivian revolt has often been called a "consumer rebellion" against the principle of water privatization of water utilities. In this instance, protests were largely fueled by high prices and the population's opposition to the anti-democratic nature of private foreign companies controlling their local water systems.

Once again, social pressure $(\odot(t))$ from an unexpected social outcome $(X(t+1))$ of wellintended decisions $(\boldsymbol{Z}(\mathrm{t}))$ resulted in new decisions $(\boldsymbol{Z}(\mathrm{t}+1))$ and water system changes $(\boldsymbol{X}(\mathrm{t}+2))$ that were not expected or foreseen.

Note that the use of public participation in the decisionmaking, and/or the use of adaptive policies that could have foreseen how the policy might fail, might have prevented the revolt. 
In this approach, the primary question asked by the analysts (at the time of making the policy) is 'how can this policy fail?' - i.e., what are its vulnerabilities. Based on the answer to this question, protections are added to the policy that can be implemented either at the same time that the policy is implemented, or that will be triggered later (when the monitoring indicates that the policy may be failing to meet its objectives). So, instead of panic or surprise; the policymakers would be prepared in advance for the possibility of increased social pressure.

\subsection{Pollutant Spills in North Carolina and West Virginia, U.S.A (Fig. 11)}

Similar to the situation in Greece, the desire to encourage industrial development and overlook environmental and health risks in the states of West Virginia and North Carolina is strong. Money that would be needed to reduce such risks is saved, and this generates political support and funding for politicians who support such policies. However wakeup calls can occur that at least temporarily can result in increased pressures ( $\odot)$ to set water quality standards and monitor their compliance. In 2014 two major chemical spills adversely affected the quality of domestic water supplies $(\boldsymbol{X})$ of many people in the two states, causing at least temporary remedial actions $(\boldsymbol{Z})$ by those responsible for public health and river water quality.

The Elk River chemical spill occurred on January 9, 2014. A considerable quantity of crude 4-methylcyclohexanemethanol (MCHM) flowed from an industrial facility into the Elk River, upstream from the principal water intake of the utility that treats and distributes water to residents of nine counties in the Charleston metropolitan area of West Virginia. Following the spill, some 300,000 residents were without access to potable (safe) water. The chemical spill was the third chemical accident to occur in the Kanawha River Valley within the last 5 years.

On January 9, the Governor of West Virginia declared a state of emergency $(\boldsymbol{Z})$ and activated the National Guard. He ordered residents within the affected area to "continue to refrain from using the water for drinking, cooking, cleaning, bathing, and washing." The U.S.

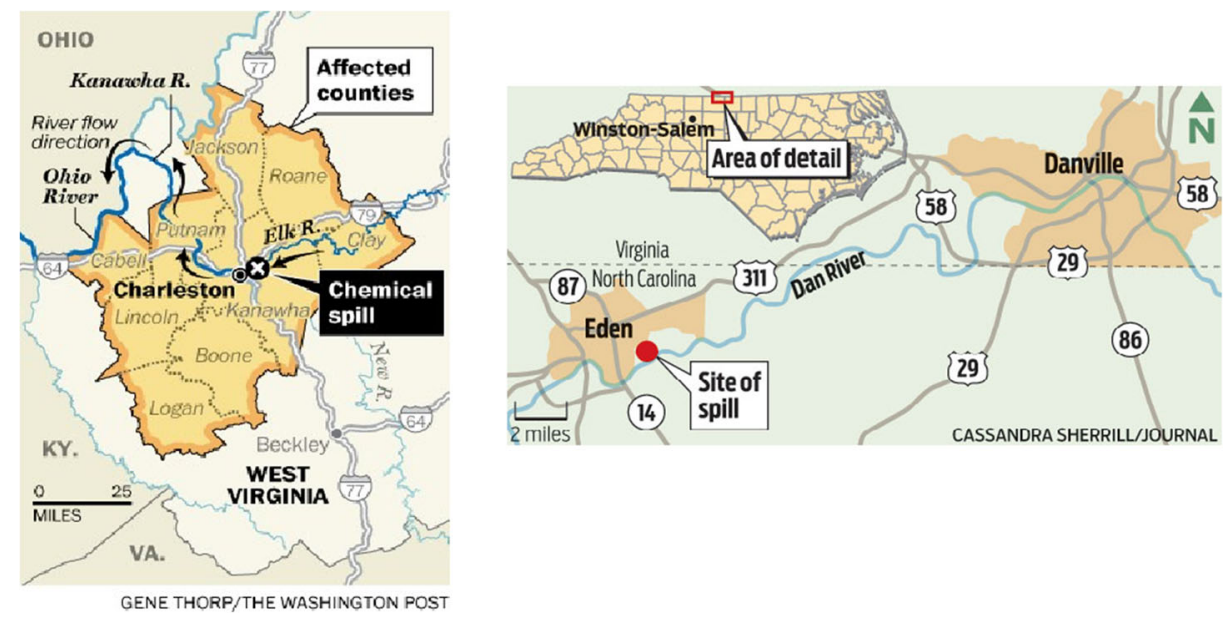

Fig. 11 Maps showing rivers and communities affected by spills of pollutants in West Virginia and North Carolina in southeastern U.S. (Winston-Salem Journal, April 12, 2015) 
President declared a Federal state of emergency $(\boldsymbol{Z})$ and directed the Federal Emergency Management Agency (FEMA) to provide both assistance on the ground and Federal funding for the state's emergency management efforts.

At the request of the Governor, the state's Department of Environmental Protection (DEP) began examining new methods of regulating similar chemical facilities ( ()). This is the same governor who made it clear upon his election that DEP was to be a friend to industry in his state.

Compared to many of West Virginia's environmental disasters, the spill was unusual; there were no casualties to count (at least in the short run) and no floodwaters to fight. It was an accident with no clear ending, andthe most basic question remains unanswered: Is the water safe? This is an interesting case study, where at least for a short period there is pressure to change and reduce environmental risks and economic vulnerabilities (-) ). So, it may be that the pressures will result in new regulations $(\boldsymbol{Z})$. But using the past as an indicator of the future suggests that in this state, the social pressures will be ignored in the pursuit of political power and money.

About a month later, a coal ash spill occurred on the Dan River near Eden, North Carolina (). Coal ash ponds created by decades of power plant operation are often stored on the banks of drinking water sources, and Duke Energy employees noticed coal ash waste was spilling into the river from one of its coal ash ponds $(\boldsymbol{X})$.

Before the spill, Dan River was one of the sites listed by North Carolina Department of Environmental and Natural Resources (NC DENR) in a lawsuit in August 2013 against Duke Energy for coal ash contamination of groundwater and surface water. In that filing, Dan River was cited for unpermitted surface water discharges and for groundwater contamination from coal ash, with violations of state standards for antimony, arsenic, boron, iron, manganese, total dissolves solids, and sulfates. A 2009 inquiry by the U.S. Environmental Protection Agency (US EPA) made multiple suggestions for studies and monitoring, but there was no regular inspection by state or federal officials. Duke's Emergency Action Plan for the site was incomplete. Ponds were unlined, multiple seeps (spills) were identified.

Duke estimates that 30,000 to 39,000 t of ash were released into the Dan River. Duke scientists continue to work closely with experts from U.S. EPA, U.S. Fish and Wildlife Service, Virginia Department of Environmental Quality, and NC DENR to study and monitor the Dan River. In response to the growing public concern ( () ) since the coal ash spill into Dan River, the Governor of North Carolina has proposed legislation $(\boldsymbol{Z})$ addressing North Carolina's problem with toxic coal ash waste. Some see the Governor's proposal as inadequate and a sweetheart deal for Duke Energy.

The Governor's proposal is similar in a number of ways to Duke Energy's desired plan for coal ash ponds in North Carolina. The Governor's plan barely creates any deadlines requiring Duke Energy to clean up its coal ash ponds, and would allow Duke to leave the ash in place at most of its sites. The bill gives Duke considerable leniency in determining what actions to take, and with few requirements $(;)$ that lead to substantial risk reductions. Duke wants to simply cap the top of many of these toxic ponds, leaving them close to waterways. This will not protect North Carolina from future groundwater and surface water contamination from toxic coal ash leaks.

In both the Elk River and Dan River cases, public concern (changes in (-) ) may be felt by those making decisions, $\boldsymbol{Z}$, affecting the water system, $\boldsymbol{X}$, but this public reaction is not strong enough to overcome the political utility, $N U$, gained by leaving $\boldsymbol{X}$ largely unchanged and by supporting the wishes of an industry that surely contributes to those who support it. 


\subsection{Water Management in Iran}

As an arid country with numerous lofty mountain chains, Iran has a predilection for building dams. Many people in the area blame the half-dozen major dams $(\boldsymbol{Z})$ the government has built in the region for the Lake Urmia's water shortage. The dams that were built in part to divert water from nearby rivers to the lake have actually reduced the flow of water to the lake. Water stored in dams motivated increased irrigation development and accompanying increases in local employment and income. This increased irrigation development has had priority over diversions to restore and enhance the ecosystems in Lake Urmia. What was expected $(E \boldsymbol{X}(\mathrm{t}+1))$ from the decision $(\boldsymbol{Z}(\mathrm{t}))$ to build dams, was not what actually happened, $\boldsymbol{X}(\mathrm{t}+1)$, at least with respect to Lake Urmia Fig. 12.

\subsection{Federal Flood Insurance in the US}

In July 2012, the U.S. Congress passed the Biggert-Waters Flood Insurance Reform Act of 2012 (BW-12), which called on the Federal Emergency Management Agency (FEMA) and other agencies, to make a number of changes to the way the National Flood Insurance Program (NFIP) is run $(\mathbf{Z}(\mathrm{t})$ ). Key provisions of the legislation required the NFIP to raise rates to reflect true flood risk, make the program more financially stable, and change how Flood Insurance Rate Map (FIRM) updates affect policyholders. The

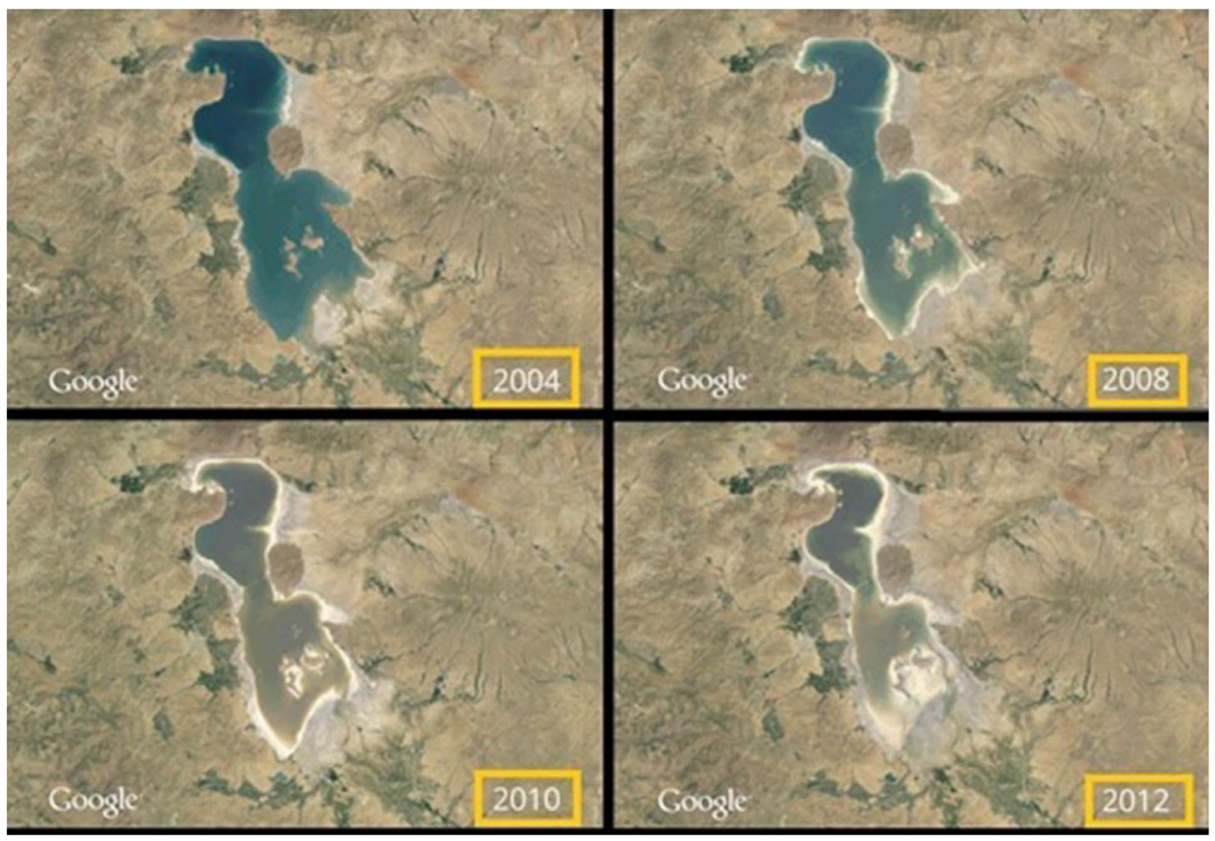

Fig. 12 Decrease of water stored in Lake Urmia in Iran over time. Iran is facing a water shortage severe enough that officials are making contingency plans for rationing in the greater Tehran area, home to 22 million persons, and in other major cities around the country. Lake Urmia, where only $5 \%$ of its normal water storage volume remains, has suffered from over allocation and withdrawals of inflowing water, and inefficient water use. Iranian President Hassan Rouhani has identified water as a national security issue, and in public speeches in areas struck hardest by the shortage he is promising to "bring the water back." (http://blog.everythingdinosaur.co.uk/blog/_ archives/2013/09/29/the-ecological-crisis-at-lake-urmia.html) 
changes resulted in premium rate increases (less Federal subsidies) for policyholders over time.

This event was historic. First of all, it was approved by a majority of both political parties in Congress, as well as by the President - a rare event these days. Secondly it was strongly supported by those who believe the cost of living or working in risky places should be borne by those receiving the benefits of so doing, and not the general tax payers. And thirdly it was supported by those interested in reducing the federal debt. Over the past decade, the cost to taxpayers of subsidizing flood prone properties has soared, with payouts for damage from Hurricanes Katrina, Irene, Isaac, and Sandy driving the Federal flood insurance program into a debt of $\$ 24$ billion.

As a consequence of the 2012 Biggert-Waters Act $(\boldsymbol{Z}(\mathrm{t}))$, those living on flood plains began experiencing substantial rate increases (Fig. 12), reflecting the actual risks of incurring losses from getting wet $(\boldsymbol{X}(\mathrm{t}+1))$. As their insurance bills increased and their property values decreased, homeowners begged lawmakers to block or delay the Biggert-Waters provisions $(\odot(\mathrm{t}))$. In the interest of maintaining happy voters, Congress introduced and passed another law, essentially rescinding the original BW-12 Act Fig. 13.

On March 21, 2014, President Obama signed the Homeowner Flood Insurance Affordability Act of 2014 into law. This law $(\boldsymbol{Z}(\mathrm{t}+1))$ repeals and modifies certain provisions of the Biggert-Waters Flood Insurance Reform Act $(\boldsymbol{Z}(\mathrm{t}))$. It is ostensibly designed to help families maintain affordable flood insurance, ensure the financial stability of the NFIP, and

\section{NFIP Rating Examples: The Impact of Loss of Subsidies}

\section{Rate comparisons}

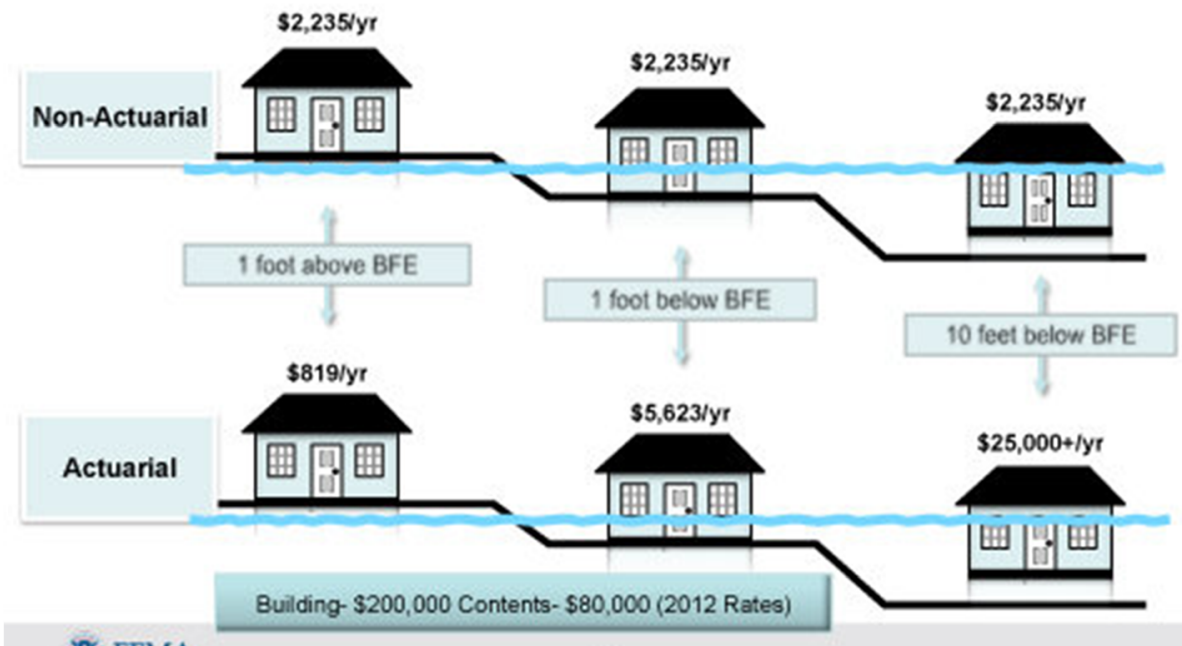

\section{FEMA}

Fig. 13 Comparison of flood insurance rates with and without subsidies from the government's National Flood Insurance Program administered by the Federal Emergency Management Agency (FEMA) (http://switchboard. nrdc.org/blogs/rmoore/flood_insurance_reforms_in_the.html) 
reduce the risks and consequences of flooding nationwide. It is really designed to maintain the status quo.

It effectively guts the 2012 law that had aimed to overhaul the bankrupt National Flood Insurance Program. The 2012 law, the Biggert-Waters Act, ended longstanding federal subsidies for insuring buildings in flood-prone floodplains and coastal areas. The revised law will keep the program in a state of insolvency. The U.S. taxpayers will continue to pay much of the cost of flood recovery.

Clearly this unpredicted reaction by Congress to bow to the wishes of the affected homeowners $(N U)$ resulted in an unpredicted change in decisions $\boldsymbol{Z}$, and consequently in the system itself $\boldsymbol{X}$.

It should be relatively easy to predict that those who are going to have to pay more for insurance are going to resist such change. What was unpredictable and a surprise is how quickly Congress gave way to their wishes, given the many political factors taking place at the same time.

\subsection{Drought Management in Santa Barbara, California}

During the period from 1986 to 1991, the City of Santa Barbara experienced a drought $(\boldsymbol{X}(\mathrm{t}))$ severe enough to motivate some homeowners to paint their dead lawn grass green. The city decided to build a desalination plant (Fig. 14) $(\boldsymbol{Z}(\mathrm{t}))$ expecting the drought to continue $(\mathrm{E} \boldsymbol{X}(\mathrm{t}+1))$. Before it could be used, rains came and filled the local reservoirs $(\boldsymbol{X}(\mathrm{t}+1))$. The desalination plant was tested, but never used. It was placed on standby and then mothballed.

Currently Santa Barbara along with the rest of California is experiencing another drought. Some City water managers are considering activating the mothballed plant. They estimate it would cost about $\$ 20$ million and take 2 years to replace the degraded reverse-osmosis membranes and outdated hydraulic and computer equipment. The computers in the operations control room, for example, were last used for the plant's test run in the early 1990s.

Under Santa Barbara's long-range water plan, the sixth year of a drought (the tipping point) would trigger consideration of bringing the plant back online. Just 4 months into the third dry year, however, that decision is years away.

City leaders are doing everything they can to delay — or avoid - reactivating the desalination plant $(\boldsymbol{Z}(\mathrm{t}))$. They are promoting conservation and finding other water sources through private vendors or the State Water Project.

While water from local lakes and reservoirs costs about $\$ 100$ per acre-foot, the desalinated water would cost about $\$ 1,500$ per acre-foot — not including any of the start-up capital costs.
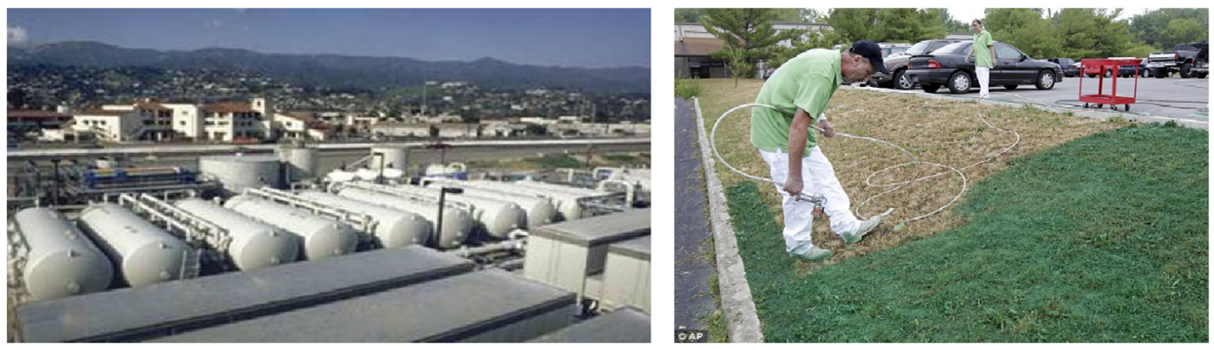

Fig. 14 Santa Barbara's water desalination plant, costing \$34 million, has been dormant since it was completed in 1992. Alternatively, there is always the option of painting dead lawn grass green. ((City of Santa Barbara photo) (http://www.dailymail.co.uk/news/article-2179882/Drought-sufferers-spray-dead-dried-lawnsgreen-using-lawn-paint.html)) 
Adding those expenses increases the cost to about $\$ 3,000$ per acre-foot $=\$ 1000$ per singlefamily household/year. The desalination facility would produce half of the city's water needs. Time will tell.

\section{Conclusions}

Water planning, management, and decisionmaking activities have technical, social, environmental, economic, and political dimensions. They involve people, as well as water. They are complex, in that the relationships between people and water involve feedbacks that lead to non-predictable evolutions of the systems. Moreover exogenous factors often have dominant consequences on systems that one would like to model. The values of many system variables, functions, and parameters are uncertain and hard, if not impossible, to estimate. Some of these variables, functions, and parameters are even hard to quantify, let alone include in planning and management models. Arguably the most intractable problems faced by those in the practice of water planning and management today are those associated with its social and political aspects. What people or their institutions do to better design, manage, or operate current and future water resource systems depends in large part on what they think their constituent stakeholders want. Reaching a consensus that makes it clear what it is that 'society' wants is not always easy. Being able to evaluate the physical, economic, and environmental consequences of any particular decision, prior to when the actual decision is made, does not necessarily make it easier to predict in advance whether or not that particular decision will be made, or what the response of the stakeholders will be. It seems to be impossible to identify all the factors and criteria individuals consider when making their decisions. This apparent 'randomness' carries over to the political and social institutions people create to establish water management policy.

Although we cannot predict social responses and subsequent decisions, or even the often surprising outcomes of our water systems, we can involve people (i.e., the social component) in the water system modeling and decisionmaking process. Models are ways to define problem boundaries and mechanisms, and to organize the discussion on water-societal problems in a quantitative way. We can do this using approaches such as shared vision planning (collaborative modeling), agent-based modeling, or smart games, coupled with the concept of adaptive policies, and possibly involving the use of interactive decision support systems as the interface between people - the social system - and the water system. We can use these approaches to draw out hidden knowledge or discover new knowledge. How the involved stakeholders react to various states of the water system will be influenced by the culture/values/norms of the society. Once all of us, including natural and social scientists and others, working together can identify such relationships, we can start to think about and hypothesize about different decisions society might make. And we can also consider the actual capacity of the society to implement their decisions in the face of uncertainty, not only in the water system but also in the changing social and political environment in which decisions are being made.

Focusing on coupled interactions between water and society (i.e., socio-hydrology) might help us understand which solutions or pathways might be better or worse according to our chosen criteria. For example, if we model dam building as a response to groundwater depletion because of agricultural water scarcity, we might be able to show that water demand increases as more reservoir water becomes available. Consequently, instead of overcoming the scarcity, 
this leads to greater groundwater depletion when reservoir supplies are insufficient to meet crop demands at certain critical times in the year. This shows us the vulnerability of the policy of building more dams.

Clearly, decisions regarding the design, planning, management, and operation of our water systems, and the creation and implementation of water resources policy, are only partially influenced by scientific studies. They are also influenced by stakeholder opinions, often expressed in the media, when there is a "water crisis" that people want addressed if not solved. It often takes a crisis to motivate change. Public pressure on social institutions often leads to change. Change can result from stress due to a 'crisis' such as an extreme drought, flood, or pollutant spill. Change can also result from learning new knowledge - e.g., information about the health of the environment, external changes in the physical environment, and changes in the interests and objectives of stakeholders. The above case events are examples of all of this. But people also resist change, and the cases show that a set of factors are often needed to bring sufficient social pressure that actions are taken to change the system.

Societal responses to demands for change cannot be predicted, but it seems evident that decision-making can be improved using approaches such as those described above, as well as an interdisciplinary approach that integrates current knowledge from both the social and natural sciences. Such knowledge of the social and cultural aspects associated with water is needed to achieve sustainable water management in a changing, uncertain, unpredictable environment. While social systems are complex and do not fit easily into the kinds of quantitative models of natural scientists and economists, we involved in planning and management cannot view 'the environment' or our 'water systems' as separate from the people who need it, use it, and do things to it.

\section{References}

Blöschl G, Carr G, Bucher C, Farnleitner AH, Rechberger H, Wagner W, Zessner M (2012) Promoting interdisciplinary education - the Vienna doctoral programme on water resource systems. Hydrol Earth Syst Sci 16:457-472, Special Issue on: Hydrology Education in a Changing World

Bouarfa, Blom H A P, Curran R, Everdij M H C (2013) Agent-based modeling and simulation of emergent behavior in air transportation. Complex Adapt Syst Model 1(15). doi:10.1186/2194-3206-1-15

Cardwell H, Langsdale S, Stephenson K (2008) The Shared Vision Planning Primer: How to incorporate computer aided dispute resolution in water resources planning. Institute for Water Resources, Alexandria, IWR Report 08-R-02

Carr G, Potter RB (2013) Towards effective water reuse: drivers, challenges and strategies shaping the organisational management of reclaimed water in Jordan. Geogr J 179(1):61-73. doi:10.1111/j.1475-4959. 2012.00478.x

Di Baldassarre G, Viglione A, Carr G, Kuil L, Salinas JL, Blöschl G (2013) Socio-hydrology: conceptualising human-flood interactions. Hydrol Earth Syst Sci 17:3295-3303

Guerts J (1993) Looking back to the future: Long term reconnaissance in policy exercises. Alphen aan den Rijn, the Netherlands: Samson

Haasnoot M, Kwakkel JH, Walker WE, Ter Maat J (2013) Dynamic adaptive policy pathways: a New method for crafting robust decisions for a deeply uncertain world. Glob Environ Chang 23(2):485-498. doi:10.1016/j. gloenvcha.2012.12.006

Jeffrey P (2003) Smoothing the waters: observations on the process of cross-disciplinary research collaboration. Soc Stud Sci 33(4):539-562

Klein JT (1990) Interdisciplinarity: History, Theory, and Practice. Wayne State University Press, Detroit

Kreuger T, Lane S, Maynard C, Mueller E, Carr G, Bruns A (2014) A transdisciplinary account of hydrology and water resources management

Kwadijk JCJ, Haasnoot M, Mulder JPM, Hoogvliet M, Jeuken A, van der Krogt R, van Oostrom NGC, Schelfhout HA, van Velzen EH, van Waveren H, de Wit MJM (2010) Using adaptation tipping points to 
prepare for climate change and sea level rise: a case study in the Netherlands. Wiley Interdiscip Rev Clim Chang 1:729-740

Kwakkel JH, Walker WE, Marchau VAWJ (2010) Adaptive airport strategic planning. Eur J Transp Infrastruct Res 10(3):227-250

Lane SN (2014) Acting, predicting and intervening in a socio-hydrological world. Hydrol Earth Syst Sci 18:927-952

Macy MW, Willer R (2002) From factors to actors: computational sociology and agent-based modeling. Annu Rev Sociol 28:143-166. doi:10.1146/annurev.soc.28.110601.141117

Marchau VAWJ, Walker WE, van Wee GP (2010) Dynamic adaptive transport policies for handling deep uncertainty. Technol Forecast Soc Chang 77(6):940-950

Mayer IS (2009) The gaming of policy and the politics of gaming: a review. Simul Gaming 40(6):825-862. doi: $10.1177 / 1046878109346456$

Michael D, Chen S (2006) Serious Games: Games that Educate, Train and Inform. Thomson Course Technology PTR, Stamford

Montanari A, Young G, Savenije HHG, Hughes D, Wagener T, Ren LL, Koutsoyiannis D, Cudennec C, Toth E, Grimaldi S, Blöschl G, Sivapalan M, Beven K, Gupta H, Hipsey M, Schaefli B, Arheimer B, Boegh E, Schymanski SJ, Di Baldassarre G, Yu B, Hubert P, Huang Y, Schumann A, Post DA, Srinivasan V, Harman C, Thompson S, Rogger M, Viglione A, McMillan H, Characklis G, Pang Z, Belyaev V (2013) PantaRheieverything flows: change in hydrology and society-the IAHS scientific decade 2013-2022. Hydrol Sci J Journal Des Sciences Hydrologiques 58(6):1256-1275

Monticino M, Acevedo M, Callicott B, Cogdill T, Ji M, Lindquist C (2007) Coupled Human and Natural Systems: A Multi-Agent Based Approach. In: Pahl-Wostl C, Schmidt S, Rizzoli A E, Jakeman A J (eds) Complexity and Integrated Resources Management, Transactions of the 2nd Biennial Meeting of the International Environmental Modelling and Software Society, Manno, Switzerland

Rahman SA, Walker WE, Marchau V (2008) Coping with Uncertainties About Climate Change in Infrastructure Planning - An Adaptive Policymaking Approach. Ecorys Research and Consulting, Rotterdam

Rittel HWJ, Webber MM (1973) Dilemmas in a general theory of planning. Policy Sci 4(2):155-169

Scharpf F (1997) Games Real Actors Play: Actor-Centered Institutionalism in Policy Research. Westview Press, Boulder

Sivapalan M, Savenije HHG, Blöschl G (2012) Socio-hydrology: a new science of people and water. Hydrol Process 26:1270-1276. doi:10.1002/hyp.8426

Taleb NN (2007) The Black Swan: The Impact of the Highly Improbable. Random House, New York

Viglione A, Di Baldassarre G, Brandimarte L, Kuil L, Carr G, Salinas JL, Scolobig A, Blöschl G (2014) Insights from socio-hydrology modelling on dealing with flood risk - roles of collective memory, risk-taking attitude and trust. J Hydrol. doi:10.1016/j.jhydrol.2014.01.018

Voinov A, Bousquet F (2010) Modelling with stakeholders. Environ Model Softw 25:1268-1281

Walker WE, Rahman SA, Cave J (2001) Adaptive policies, policy analysis, and policymaking. Eur J Oper Res 128(2):282-289

Walker WE, Lempert RJ, Kwakkel JH (2013) Deep Uncertainty. In: Saul I, Michael C (eds) Encyclopedia of Operations Research and Management Science. Springer, New York, pp 395-402

Wood M (2014) The move toward computing that reads your mind, Personal Tech. New York Times 8:B7 